the prompt recognition and isolation of suspicious cases of diarrhoea we can confidently hope for comparative immunity from the fell disease. or rather diseases which have been the scourge of all armies in the field since the day of Agincourt.

Bibliography. ${ }^{-1}$ C. Birt: Dyeentery. Journal of the Royal Army Medical Corps, vol. ii., p. 147. 2 C. Birt, The Selective Action of Caffeine on Colon, Dysentery, and Typhoid Bacilli, ibid., vol, v., p. 731 . 3 Birt and Eckersley : The Flagella of Dysentery Bacillus, ibid. vol. iv.,p. 138. 4 R. Brown: The Bacteriology of Asylum Dysentery, ibid, vol. i., p. 425 . 5 . Bruce: Report of the Commission on the Nature, Pathology Causation, and Prevention of Dysentery, \&c., appointed by the Secretarv of State for War, 1900. 6 W. J. Buchanan: Dysentery its Form and Treatment, Practitioner, December, 1897 p. 600 . 7 W. J. Buchanan: The Salire Treatment of Dysentery, Brit. Med. Jour. Feb. 10th, 1900, p. 306. ${ }^{*}$ W. J. Buchanan : Dysentery as a Terminal Symptom of Disease in the Tropics, ibid., Sept. 9th, 1899,

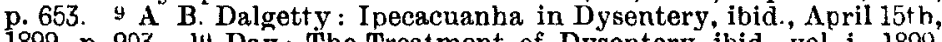
1899. p. 903. 1" Day : The Treatment of Dysentery, ibid., vol, i., 1899, p. 272. 11 Davidson: Article on Dysentery in Clifford Allbutt's System of Medicine, vol. ii., p. 409. 12 Dopter : Transmissibility of Amœebic Dysentery in Europe, Ti E La arceT, Dec. 3rd, 1904, p. 1583 . 13 Dopter: Bulletin de la Société Médicale dés JLôpitaux, July 7th, 1905, p. 654 . 14 J. H. Eyre : Bacteriological Technique (Saunders, 1902). 16 Ewart The Principles of Treatment in Typhoid Fever, Brit. Med. Jour., The Principles of Treatment in Typhoid Fever, Brit. Med. Jour. Dec. 10th, 1902. 16 N. Faichnie : Varieties, Causation, and Treatment
of Dysentery on Active Service, ibid.. August 12/h, 1905, p. 325 . of Dysentery on Active Service, ibid.. August 12lh, 1905, p. 325. 17 G. H. Fink : Drsentery in Active Service, Indian Medical Gazette,
January, 1898. $18 \mathrm{R}$. H. Firth : A Comparative Study of Some Dysenterv Bacilli. Journal of the Royal Army Medical Corps, vol. i.. p. 436 19 R. H. Firth: Bacillary Dysentery, ThE LANCET. 1904, vol. i , p. 800. 20 R. H. Firth: The Present Position of the Dysentery Question, lecture at the Royal Army Medical College, November, 1905. 21 S. Flexner: Report on Expedition sent by the Johns Hopkins University to the Philippines (Brit. Med. Jour.. 1901, vol. ii., p. 786). 22 German Association of Public Health, Means of Preventing Dysentery, The LancFi, Oct. 8th, 1904, p. 1052. ${ }^{23}$ Hare: Text-book of Practical Therapeutics, 1904. 21 Manson : Tropical Diseases (Cassell and Co., 1903). ${ }^{25}$ Maberly : Dysentery and its Treat ment, The Lancet, Feb. 6th. 1897, n. 308. 26 Muir and Ritchie : Manual of Bacteriology (Young J. P'entland, 1902). 27 F. L. Munson: Militarv Hygiene (Bailliêre, Tindall, and Cox, 1900). 23 J. C. F. Nash: The Diet of Typhoid, Brit. Mer. Jour., Dec. 10th, 1905. ${ }^{29}$ W. Osler : The Principles and Practice of Medicine (Appleton and Co., 1905). 30 Rogers. Brit Med. Jour, vol, $i, 1903,0.1316$. 3: Rouget: Magnesium Sulphate Med. Jour, vol. i., 1903, p. 1316. 3: Rouget: Magnesium Sulphate in Typhoid Dysenterv, ibid., Nriv. 18th, 1899, p. 1413. 33 Scheube Diseases of Warm Countries (John Bale, Sons, and Danielsson), 1903. 33 Stengel : Text-book of Pathologv (Saunders, 1904). 34 William Stewart: Ammonium Chloride in the Treatment of Tropical Dysen tery, Brit. Med. Jour., Sept. 24th, 1898, p. 890, 35 Frederick Tavlor: The Practice of Medicine. seventh edition (Churchill) Vaillard et Ch. Dopter: La Dvsentérie Epidémique, Annales de Institut Pasteur, tome xvil., No. 7 , July 25 th, 1903, p. 463 37 Vincent: Archives de Médecine et de Pharmacie Militaires, cuoted in The Lancet, 1904, vol. i., p. 317. 3s Washbourn: Notes on Gastro-enteritis, Dysenterv, and Enteric Fever, Brit. Med. Jour. vol. i., 1900, June 16th. 39 Burney Yeo. Manual of Therapeutics, vol. i. (Cassell and Co., 1933). 40 (. B. Sheldon Amos: A Note on the Treatment of Catarrhal and Gangrenous Dysentery, ThE LavcE'T, August 4th, 1906, p. 295 . 4l F. A. F. Barnardo : Scury in Somaliland: Notes on the Condition of the Blood Serum, Indian Medical Gazette No. 7, July 7th. 42 F. J. McWeeney: On the Relation of the Para sitic Protozoa to Each Other, Transactions of the Fpidemioloyical Society of London, N.S., vol. xxiv., 1904-05, 43 E. J. McWeeuey Presidential Address in the pathological Section, Transactions of the Royal Academy of Medicine in Ireland, vol xx, 1902, 4t Schaudinn: Arbeiten aus dem Gesundheitsamte, Dand xix, 1903 ; Centralblatt fur Bakteriologie, 1893. 45 Castellani : Journal of Hygiene, vol. iv., p. 508.

\section{A CONTRIBUTION TO THE STUDY OF PHLYCTENULAR OPHTHALMIA.}

BY J. B. NIAS, M.D. Oxon,, M.R.O.P. Lond., PUYSICIAY TO THE WESTERN GENERAL DYSPENSARY, MARYLEBONERUAD, N.W.

$$
\text { IN1) }
$$

LESLIE PATON, M.B. CANTAB., F R.C.S. ENG.,

OPHTHALMIC SURGEON TO ST. MARY'S HOSPI'LAL, PADDINCTON, (From the Pathologioal Laboratory of St. Mary's Hospital.)

THE idea that phlyctenular ophthalmia is due to infarctions of dead or attenuated tnbercle bacilli has occurred to many clinical observers. It is a hypothesis that suits very well the recognised features of the disease. but no direct verification has hitherto been obtained in support of it either from the histological or from the experimental side. By a recent employment, however, of the delicate methods invented by $\operatorname{Sir}$ A. F. Wright and his collaborators for measuring the fluctuations that are produced in the opsonic power of the blood by the invasion of pathogenic organisms, we believe that we are able to throw some light upon this vexed question.

During the past 12 months, acting upon a suggestion of Sir A. F. Wright, we have been testing the opsonic power of the blood against the tubercle bacillus in all cases of phlyctenular conjunctivitis that have presented themselves in the out-patient department of St. Mary's Hospital. The number so examined is now well over 50 and the samples of blood examined amount to nearly 200 , so that we may claim to have establisked a broad basis for our conclusions. A preliminary note on the results was presented to the Ophthalmological Society in November. 1905, ${ }^{1}$ in which, without putting forwarcl any very positive conclusion, we were able to announce that the blood of such patients behaved in a manner which was altogether typical of a definite tuberculous infection-that is to say, that its activity in opsonic action on the tubercle bacillus fluctuated in a marked and definite manner above and below the normal according to the progress of the case. Since that time we have proceeded in a more elaborate fashion by procuring the attendance of patients at the laboratory for the daily sampling of their blood, and it is a selection from the much more conclusive clata so obtained that we wish to submit on the present occasion.

The blood of a patient suffering from genuine phlyctennlar ophthalmia is generally found to be markedly deficient in opsonic power to the tubercle bacillus but not to other bacteria, such as the staphylococcus, at the ontset of the case, but if the patient be adequately treated (without recourse to tuberculin, be it understood) the opsonic index rapidly rises and reaches a maximum coincidently with the healing of the ulcers. It then begins to fall rapidly and in a few days is far below the normal, as if from exhaustion of the mechanism. At this low figure it will remain if the observations be continued for an indefinite time, and if, as so often occurs, a relapse takes place the same stquence of phenomena will be reproduced. In a minority of cases, generally older and more vigorous subjects, the opsonic index as regards tabercle will be found to have risen already much above the normal. Here it will remain with temporary falls till healing occurs and then takes a terminal drop as in the former category. We have not yet met with a single exception to this course of phenomena in phlyctenular conjunctivitis.

The simplest type of case is presented in Chart 1. The

Chart 1

\begin{tabular}{|c|c|c|c|c|c|c|c|c|c|c|c|c|c|c|c|}
\hline \multicolumn{7}{|c|}{ JAN } & \multicolumn{9}{|c|}{ FEB } \\
\hline 0.1 & 25 & & \begin{tabular}{|l|l|}
27 & 28 \\
\end{tabular} & 29 & 303 & 31) 1 & 12 & 21 & 3. & 4 & 5 & 0 & 7 & 8 & 9 \\
\hline 1.5 & & & & & & & & & & & & & & & \\
\hline 1.4 & & & & & & & & & & & & & & & \\
\hline 1.3 & & & & & & & & & & & & & & & \\
\hline 1.2 & & & & & & & & & & $Z$ & & & & & \\
\hline 1.1 & & & & & & $x$ & & & $\Lambda$ & & & & & & \\
\hline 1.0 & & & & & & & & & & & & & & & \\
\hline .9 & & & & & $\therefore$ & & & & & & & & & & \\
\hline .8 & & & & & & & & & & & & & & & \\
\hline .7 & & & & & & & & & & & & & & & \\
\hline .6 & & 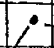 & - & $1 !$ & & & & & & & & & & & \\
\hline .5 & 1 & & & & & & & & & & & & & & \\
\hline 4 & 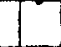 & & & & & & & & & & & & & & \\
\hline
\end{tabular}

Chart of opsonic index. X, Disappearance of ulcer.

patient, a girl, aged 18 months, was a badly nourished child who was taken to St. Mary's Hospital for a well marked ulcer on the margin of the cornea on August 18th, 1905, with the usual photophobia and blepharo-spasm. Treatment was initiated with iodide of iron, atropine ointment, and fomentations, and the patient continued in attendance until Oct. 31 st, when she was discharged cured. The blood was only examined for its opsonic index on one occasion during this attack-namely, on Sept. 1st, and the index was found to be 1.0-i e., normal. On Jan. 25th of the present year she was brought back with a fresh attack and this time it was determined to have a complete record of the case. Accordingly the mother was persuaded to bring the child as nearly as possible daily to the laboratory and the annexed chart was obtained The eje presented a single phlyctenular ulcer on the edge of the right co nea: yellow oxide of mercury ointment was used on this occasion with a mixture of rhubarb and soda internally, the child's

1 Transactions of the Ophthalmological Society of London, rol. xxvi. p. 232 . 
digestion being disordered. In a week's time the ulcer had healed and the chart shows that during that time the opsonic index had steadily risen from 0.5 to 0.95 . It continued to rise to 1.5 and fell to $1 \cdot 2$. The child was then transferred to the medical department and attended there until the 23rd, when she was discharged. We have not seen her since.

No very palpable tuberculous lesion could be detected in this child, though the usual surmises may be made as to the existence of enlarged mesenteric glands and so forth. In the present state, however, of our knowledge as to the effect on the blood of declared tuberculous disease it is difficult to believe that such a chart could be derived from a patient without a slumbering focus of tuberculous disease somewhere in the body. The great majority of cases of phlyctenular ophthalmia yield charts of this type.

Chart 2 is a less pronounced instance of the same class. The patient, aged 10 years, was a healthy-looking boy who came to St. Mary's Hospital on Jan. 9th of

ChaRT 2.

\begin{tabular}{|c|c|c|c|c|c|c|c|c|c|c|c|c|c|c|c|}
\hline \multicolumn{16}{|c|}{ JAN } \\
\hline o.1. & 10 & 11 & 12 & 13 & 14 & 15 & 16 & 17 & 18 & 19 & 20 & 21. & $22:$ & $\begin{array}{ll}23 & 2\end{array}$ & $24 \mid 25$ \\
\hline 1.4 & & & & & & & & & & $x$ & & & & & \\
\hline 1.3 & & & & & & & & & & 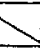 & & & & & \\
\hline 1.2 & & & & & & & & & & & 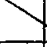 & & & & \\
\hline 1.1 & & & & & & & & 1 & & & & & & & \\
\hline 1.0 & $i$ & & & $\therefore$ & & $\rightarrow$ & & & & & & & & $\nabla$ & \\
\hline .9 & & & 8 & & & & $V^{\prime}$ & & & & & & & & \\
\hline .8 & & $?$ & & & & & & & & & & & & & \\
\hline .7 & & & & & & & & & & & & & & & \\
\hline .6 & & & & & & & & & & & & & & & 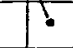 \\
\hline
\end{tabular}

Chart of opsonic index. X, Disappearance of ulcer.

the present year with two marginal ulcers on the right cornea and three on the left. His clinical history was good, but he had undoubtedly had two attacks of the same affection before. Treatment was begun with yellow oxide ointment, fomentations, and iodide of iron. By attendance at the laboratory a very satisfactory chart (Chart 2) was obtained; the opsonic index was found to hover around the normal for several days and then rose to $1 \cdot 4$, to be followed by the usual terminal drop to 0.67 . The ulcers began to improve after four days' treatment and were gone in a week. On August 3rd this boy returned to the hospital with a doubtful kind of conjunctivitis on the outer side of the left eye said to have followed a blow. Arrangements were made to obtain a fresh cbart, but had to be abandoned from press of other work. Three samples of blood were, however, tested as follows: August 3rd, 0.47; Angust 4th, 0.74; August 6 th, $1 \cdot 20$; therefore, this was probably the development of anotker ulcer which would have followed the usual course

A condition which occurs in 8 or 10 per cent. of the cases is shown in Charts 3 and 4 . Here the patient's blood is found to be far above the normal in its opsonic power towards the tubercle bacillus, presumably from having risen before the patient comes under observation. It is generally older and more vigorous patients who show this prompt reaction. Chart 3 is that of a girl, aged 14 years, who had ju-t recovered from an attack of chicken-pox. She presented two typical ulcers on the right eye and one on the left. A history was given of a former attack a year previously and some enlarged glands could now be felt in her neck. Treatment consisted of a mixed ointment of yellow oxide and atropine fomentations and iodide of iron. Through the goodwill of the patient an excellent chart was procured; and in view of the anomalous figures obtained great pains were taken with the estimation of the blood, which we believe to be quite correct and free from errors of technique. If there be any value whatever in the method of research elaborated by Sir A. E. Wright and his co-workers this is a surprising example of the results which it yields. Clinically there was nothing remarkable about the aspect of the case and yet the blood was undergoing these marked variations in its com. position or activity. It will be seen that at first the opsonic index ranged from $1 \cdot 6$ to $1 \cdot 8$; then from what we are tempted to consider an over-production of the protective sub. stance, what Sir A. E. Wright has denominated a "negative phase," ensued ; and the opsonic index fell on two successive days to 0.47 . So surprising was this that the samples of blood were worked twice over. A final rise took place to 1.7 and the ulcers healed. Feb. 10th was a Saturday and the estimation of the blood was finished before the patient's arrival on Monday; from the figure of the opsonic index it was predicted that the ulcers would be quite healed, as was the case. On the strength of our experience we can

CHART 3.

\begin{tabular}{|c|c|c|c|c|c|c|c|c|c|c|c|c|c|c|}
\hline & $\mathrm{FE}$ & & & & & & & & & & & & & \\
\hline O.1. & 2 & \begin{tabular}{l|l}
3 \\
\end{tabular} & 5 & 6 & 7 & 8 & 9 & \begin{tabular}{l|l}
10 & 11
\end{tabular} & 12 & \begin{tabular}{|l|l|}
13 & 1 \\
\end{tabular} & 141 & $15 \mid 16$ & $\mid 17$ & \begin{tabular}{l|l|l|l}
8 & 19 & 20
\end{tabular} \\
\hline 1.8 & & & & & & & & & & & & & & \\
\hline 1.7 & & & $i$ & & & & & & $x$ & & & & & \\
\hline 1.6 & 7 & & & & & & & $N$ & & & & & & \\
\hline 1.5 & & & & & & & & & & & & & & \\
\hline 1.4 & & & & & & & & & & & & & & \\
\hline 1.3 & & & & & & & & & . & & & & & \\
\hline 1.2 & & & & & & & & & & 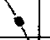 & & & & \\
\hline 1.1 & & & & & & & & & & & & & & \\
\hline 1.0 & & & & & & 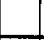 & $T$ & & & & 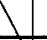 & & & \\
\hline .9 & & & & & & & & & & & & & & \\
\hline .5 & & & & ! & & & & & & & & 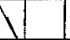 & & \\
\hline$\cdot 7$ & & & & 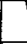 & & & & & & & & & & \\
\hline .6 & & & & & & & & & & & & & S & \\
\hline 5 & & & & & & 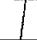 & & & & & & & & F. \\
\hline .4 & & & & & 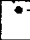 & $\because$ & & & & & & & & \\
\hline
\end{tabular}

Chart of opsonic index. $X$, Disappearance of ulcer.

ChaRT 4.

\begin{tabular}{|c|c|c|c|c|c|c|c|c|c|c|c|c|c|}
\hline \multicolumn{14}{|c|}{ MARCH } \\
\hline 0.1. & $G$ & 7 & 8 & 9 & 10 & 11 & 12 & 13 & 14 & 15 & 16 & 1718 & 1920 \\
\hline 1.7 & & & & & & & & $x$ & & & & & \\
\hline 1.6 & & & & & & & 4 & & & & & & \\
\hline 1.5 & & & & & & & & & & & & & \\
\hline 1.4 & & & & & & 1 & & & & 1 & & & \\
\hline 1.3 & & & & & & $\sqrt{ }$ & & & & $\pi$ & & & \\
\hline 1.2 & & & & & & & & & & & & & \\
\hline 1.1 & & & & & $i$ & & & & & & & & \\
\hline 1.0 & & & & & & & & & $\pi$ & & 1 & & \\
\hline .9 & & & & & & & & & $T$ & & $\gamma$ & & \\
\hline .8 & & & & & & & & 1 & & & & 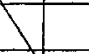 & \\
\hline .7 & & $i$ & & & & & & VI & & & & & \\
\hline .6 & & & & & & & & & & & & & \\
\hline .5 & & & & 1 & & & & & & & & & 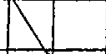 \\
\hline .41. & & & & 1 & & & & & & & & & X \\
\hline .3 & & & & & & & & & & & & & \\
\hline
\end{tabular}

Chart of opsonic index. X, Disappearance of ulcer.

now foretell eitber the speedy healing of an unpromising looking case or the protable delay in the final cure of a conparatively trivial one. Never in our experience do phly tr nules get well withort this rise in the opsonic power.

In-re is not room on the chart to display an interesting relapse which this girl had. From Feb. 20th her index continued to fall until on the 25th it descrnded to $0 \cdot 30$ that is, practically, her serum had no opronic power on the tubercle bacillus. On the 27th she developed a fresh phlyctenule in the left eye; on March 6th the index had risen again to $1 \cdot 75$, and on the 7 th this ulcer too disappeared. The patient now developed a gumboil and boils in the axilla and was ill for a week. This did not affect in the least the index to tubercle which was again 175 on the 13th; from this print it declined until at her weekly visit on the 20th it was 0.45 . From this it rose again to 0.85 , when ber attendance at the hospital finally terminated, she being then in good health To those who have not followed the restarches of Sir A. E. Wright and his school upon the subject of the opsonic power of the blood these figures may seem unmeaning; but to others they are full of significance and it is difficult to escape 
from the conclusion that in this patient we were studying the vagaries of a genuine tuberculous infection.

Chart 4 is that of another girl, aged 16 years, from whom we were able to obtain a very complete record. The clinical notes of the case are missing, but it needs no comment. It is introduced principally to show a second instance of the sudden intermediate drop which we have ascribed to overproduction of defensive substance; in this case there was no relapse.

The foregoing are typical examples of the results which we have obtained from a long series of carefully investigated cases of this affection, treated without having reconrse to tuberculin, which would, of course, vitiate the results. Several times we have been tempted to have recourse to this agent but have always found the established methods of treatment equal to the occasion if carefully and assiduously applied. We may therefore characterise the cases as on the whole left to themselves.

Before entering on any elaborate discussion of the phenomena we have described, our first desire, of course, is to bave them verified or contradicted by other observers, to whom, however, we would suggest one caution-namely, not to be satisfied with mere casual estimations of the opsonic index in this or that case but to follow it through to the end and face the labour and trouble involved, which may be considerable. All we shall say now is that our observations in the present state of our knowledge go far to furnish support for the hypothesis of Leber and other eminent authorities that these ulcers are due to attenuated or dead bacilli escaped from some unidentified focus of tuberculous disease, either free or taken up by leucocytes and not having sufficient vitality to generate a typical tuberculous lesion at their new site.

The starting point of this investigation was the occurrence of a certain number of cases of undoubted phlyctenular ophthalmia among patients who were attending the pathological laboratory of St. Mary's Hospital for treatment of various tuberculous affections by regulated doses of tuberculin. It appeared to Sir A. E. Wright that the coincidence was more than accidental and he invited us to examine the subject systematically with the result set forth. For much sympathetic advice and assistance we have to tender him our best thanks, as also for the unlimited use of the facilities of his laboratory.

\section{CEREBRO-SPINAL MENINGITIS IN THE SUDAN.}

By C. Ll. NEDWILL, M.B. Cantab., M.R.C.S. ExG., L.R.C.P. LOND.,

MEDICAL INSPECTOR OF RAILWATS TO THE SUDAN GOFERNMENT.

IN recording an epidemic of cerebro-spinal meningitis which occurred in the Nubian desert at the recent railhead of the line into the Dongola Province, it is with the hope that my notes may be of interest to those who have been following the recent reports in THE LANCET on this disease and may perhaps be of some value to those who may at any time meet with this ferer. My excuse for wishing to publish these cases must be credited to the fact that even the most incomplete notes on an epidemic of this kind must necessarily be of some use in diagnosis when we consider how variable in its onset and course this form of meningitis can be and how grave the after-effects may prove to the patient.

The epidemic under notice comprised 22 cases which extended over the months of June, July, and August, 1905. The canse of the outbreak could not be traced but coincident with this epidemic there were a few isolated cases in Halfa and one or two suspected cases of the same disease at the Suakin railhead. Though most of these other cases that were reported as being meningitis were among the workmen on the construction of the new lines and among men who might have been in contact with them at any time, set there were several instances of the fever in men who had not been near the railway and had not run any risk of infection from others who had. It has been suggested that the disturbance of the earth in making the railway has been the means of setting the diplococcus free. This would not hold in the case of those who had not been near the railway and probably the di zease is not directly contagious or transmitted by clothing or through excretions. The end of May and tre month of June comprise the hottest and most trying period in the year in this part of the Sudan, the shade temperature beingusually about $112^{\circ} \mathrm{F}$. and of ten four or five degrees higher at midday and at night falling to $70^{\circ}$ or perhaps to $60^{\circ}$. During this time also the dust storms $(h a b, u b s)$ are very trying and add greatly to the general discomfort from the heat.

The predisposing causes of the epidemic undoubtedly wereover-exertion and long hours of manual labour in the blazing sun. Though the natives were concentrated in small tents they generally, if not always, slept outside the tents, and even had they slept within it would have only been what they are accustomed to in their own villages where they crowd together in mud huts with little or no ventilation or light. The chief predisposing cause seems to bave been the hard work during the midday. The native is accustomed to resting out of the sun during midday; consequently the extra work and long hours suddenly thrown upon him in the rail. way construction were responsible for his falling a victim to tbis condition. The fact that there have been several isolated cases of cerebro spinal meningitis during this June and July at the new railway headquarters at Atbara may point to the time of the year having some connexion with the outbreak, but whether from the rising of the Nile and Atbara rivers or no there is no evidence. From the symptoms and signs in many of these cases it will be apparent that many could hardly have been diagnosed as such had they occurred sporadically. I regret to say that the routine treatment of lumbar puncture was impossible to carry out through the absence of the necessary apparatus at the railhead, and for a like reason the microscopical and pathological examinations could not be taken advantage of. The only postmortem examination that was obtained showed characteristic signs as far as they went, but further necropsies were not feasible on account of the antagonistic feelings of the natives in regard to such examinations and even in regard to submitting to treatment at all in the hospital. It may be of interest to know that it is a common belief in the Sudan that when a man is unconscious or delirious he is supposed to have devils in the head, and the only way to drive these devils out is by collecting as many of the women of the village as it is possible to congregate around the sick man. Then these women, with the help of the tom-tom and the weirdest screechings, certainly drown the wildest delirium of any one patient, because the din that is made can only be imagined by any who have been unfortunate enough to hear it. These wailings and screechings continue for hours, and when one thinks of the intense headache that the se patients suffer from, it is evident why they quickly die when they become ill enough to deserve this treatment.

The majority of the Kereima workmen had never before been to a hospital or seen an English medical man, and through fear and ignorance they lied to every question and gave the most inaccurate statements concerning themselves and their symptoms. Even when they know the hakim (doctor) and of their own accord report themselves at the hospital their statements are worthless; but in the days when they feared the hospital and everything connected with it their history as obtained from them and their relatives was worse than useless. Thus it was impossible to get any detailed account of their previous history or of the onset of symptoms beyond the immediate signs which were apparent to the dullest intellect. What information was given by the patient or by his friends or relatives was wholly untrustworthy.

Symptoms.-As far as could be obtained with any accuracy the history previously to admission amounted to the follow. ing. Four of the patients had vomited, one had had nausea, eight had complained of having been constipated for seven. two, and three days respectively, and two had complained of pain in the abdomen. What was noted concerning the remaining cases can be seen in the appended tabulated summary. Of the 22 patients treated in the hospital, 20 had been working at the railhead. Out of these, no less than 11 had been at work on the day previous to admis. sion, and of the 11, three had been at work on the day of admission. 11 out of the 22 patients were between the ages of 17 and 22 years; of the remaining 11 , two were said to be 40 years old and the other nine were between 23 and 35 years of age. The majority were badly nourished and weakly-looking individuals, though in a few cases (e.g., Case 6) the reverse condition held true. A nasal discharge was present in Case 18 only. In Case 10 the patient had a well-marked secondary syphilitic eruption 